EMBRYARIDDLE
Aeronautical University

SCHOLARLY COMMONS
International Journal of Aviation, Aeronautics, and Aerospace

\title{
The Application of Shared Leadership in an Aviation Maintenance MTS Environment
}

\author{
Bettina M. Mrusek \\ Embry Riddle Aeronautical University, mrusekb@erau.edu
}

Follow this and additional works at: https://commons.erau.edu/ijaaa

\section{Scholarly Commons Citation}

Mrusek, B. M. (2017). The Application of Shared Leadership in an Aviation Maintenance MTS Environment. International Journal of Aviation, Aeronautics, and Aerospace, 4(3). https://doi.org/ 10.15394/ijaaa.2017.1182

This Literature Review is brought to you for free and open access by the Journals at Scholarly Commons. It has been accepted for inclusion in International Journal of Aviation, Aeronautics, and Aerospace by an authorized administrator of Scholarly Commons. For more information, please contact commons@erau.edu. 
Poor communication between personnel in the aviation industry has resulted with countless aircraft mishaps (US Naval Safety Center, 2013; Schmidt, Schmorrow, \& Figlock, 2000), many of which could have been avoided. Unfortunately, the high-stress environment in which industry operates contributes to this causal factor; when aircraft are grounded due to maintenance, businesses lose money or military operations halt. As a result, the pressure to complete the necessary maintenance actions often compromises efficient communication practices.

An aviation maintenance department is comprised of several sections, many of which are interrelated. While each of these departments has different responsibilities, the collaboration of these sections is often required for the repair and replacement of components. For example, if an aircraft was grounded due to both engine and navigational system errors, it may require avionics, power plants, and airframe technicians to address the issues and achieve an appropriate state of airworthiness. If each of these errors is viewed individually, as, from a department view, the time to complete the tasks and repair the aircraft could be lengthy; especially if extensive troubleshooting is involved to identify the root cause of the malfunctions (Chandler, 2000). If, however, in this scenario, there was a team of highly qualified technicians from each of the related departments to assess and supervise the situation as one maintenance error, an appropriate solution could be identified in a more efficient, and potentially safe, manner. Once a course of action was determined, technicians could be dispatched and the components or systems fixed. Multiple problems could be worked simultaneously and collaboratively. This is an example of shared leadership in an aviation maintenance MTS environment. By leveraging the leadership and expertise of qualified technicians, organizational objectives, such as the repair of an aircraft, become a common and unified goal, as opposed to multiple actions taken by separate departments (Ensley, 2006). While this level of communication may not be appropriate for every maintenance action, those which required interdepartmental collaboration may be an appropriate environment for which to apply shared leadership. For those scenarios which meet the requirements, adjusting the distribution of leadership may positively impact organizational output. The Contingency Theory would allow for such an examination, as it is predicated on the notion that altering an organizational construct, such as the management of personnel, directly impacts organizational output. Examining shared leadership in an aviation maintenance MTS environment, through the application of the Contingency Theory, therefore, would contribute to current research on common leadership in an MTS environment and whether or not changes in management constructs, such as leadership, impacted organizational output.

\section{Background}

To understand the application of shared leadership in an aviation maintenance MTS environment, the foundational concepts in which this theory is predicated on must first be explained; shared leadership, multiteam systems (MTS), and the aviation maintenance environment. For it is the unique combination of these three, specific entities that create an opportunity in which efficiency is maximized and safe maintenance conducted. In doing so, organizational goals are achieved.

Traditionally, leadership has been applied vertically in organizations, from the top managers (Hambrick \& Mason, 1984). Information flowed from the upper echelon, in an effort to assert influence, achieve goals, and as a primary method for the implementation of strategic 
decisions. Over time, however, the responsibility shouldered by this single person grew (Ford, Heaton, \& Brown, 2001). Cost reduction and efficiency improvements were necessary elements for success. The nature of the workforce itself was also changing. The needs of personnel were not as simplistic as they were in previous decades; a sense of worth, accomplishment, and success were now integral values of the workforce (Kouzes and Posner, 2007). To navigate this new business environment, leaders soon realized that in order to create long-term organizational success, new approaches to leadership were needed (Ford, Heaton, \& Brown, 2001). A full utilization of workforce knowledge was necessary to remain competitive. Out of this revelation arose a concept in which there was not only a single leader who possessed the required knowledge to meet current and anticipated demands, while simultaneously managing multiple business entities, but a team of leaders who shared this responsibility (Pearce, 2004). This concept is known today as Shared Leadership.

However, these teams must be formulated with considerable thought. They should be comprised of subject matter experts (Friedrich et al., 2009), whose technical competence is necessary; notably for assignments that require interdependence, creativity, and are complex (Pearce, 2004). Tasks of a routine nature would not be appropriate for shared leadership, given the lack of complexity and creativity needed for the completion of assigned duties. The design and establishment of these teams are accomplished by a leader in the organization, with vertical authority. This individual must not only identify and justify the need for shared leadership, but also establish clear goals, boundaries, and team-member roles for the group (Pearce, 2004). An absence of clarity in these items contributes to a lack of coordination and ultimately, a failure in the completion of the assigned tasks (Pearce, 2004).

For those leaders that can successfully establish and incorporate shared leadership, the resulting impact could be profound. Studies have shown that the inclusion of shared leadership as a means of accomplishing organizational goals improves not only the efficiency of tasks but also the quality of output (Bienefeld \& Grote, 2014). As a result, over the last several decades, the use of team-based assignments has increased substantially in an effort to leverage the knowledge and skill sets of a firm's most qualified workers (Ensley, 2006; Pearce, 2004).

As the application of shared leadership grew, the notion of a multi-team system arose. With a firm establishment in the effective use of teams to pool the knowledge of a firm's most qualified personnel, the consideration of a system of teams surfaced. Known as multi-team systems (MTS), Mathieu, Marks, and Zaccaro defines this term as:

Two or more teams that interface directly and interdependently in response to environmental contingencies toward the accomplishment of collective goals. MTS boundaries are defined because all teams within the system while pursuing different proximal goals, share at least one common distal goal; and in doing so exhibit input, process, and outcome interdependence with at least one other team in the system. (2001, p. 964)

While this definition is similar to the concept of shared leadership, they are in fact, two, separate entities. An MTS environment is one in which several different teams, or groups of individuals, must work together in order to achieve a common, organizational goal (Mathieu, Marks, \& Zaccaro, 2001). While shared leadership, on the other hand, is a type of leadership in which several 
individuals shoulder the responsibility of accomplishing organizational tasks (de Vries, Hollenbeck, Davison, Walter, \& van der Vegt, 2016; Mathieu, Marks, \& Zaccaro, 2001). Based on these definitions, shared leadership could be applied to an MTS environment. Given that the application of shared leadership has been shown to improve the efficiency and accomplishment of organizational goals, it could also be applied to those environments which exhibit MTS characteristics. The concept of MTS is predicated on the notion of two or more teams that interact directly and interdependently; ensuring that those teams are comprised of highly knowledgeable workers, for specific or predetermined tasks allows for a more advanced application of shared leadership.

In aviation maintenance, to repair and replace certain aircraft components, some departments must work in conjunction with others, such as avionics, airframes and power plants, for example. While some tasks may be department-specific, others are not. However, these tasks are often done in separation, vice aggregation. It is not until a specific component cannot be removed without the assistance of another department that individual groups must come together. If, however, a team of qualified personnel, which included one or more representatives from each of the related departments, came together to brainstorm and troubleshoot the errors as a single problem, a more efficient course of action could be identified. In doing so, both department and organizational goals could be achieved in an effective and safe manner. By applying shared leadership, and subsequently increasing the level of communication between multiple departments, expertise can be leveraged when necessary, in order to increase the efficiency of certain maintenance actions. Research has shown that poor communication between maintenance personnel negatively impacts safety and contributes to aircraft mishaps (US Naval Safety Center, 2013; Schmidt, Schmorrow, \& Figlock, 2000). Improving communication laterally across the maintenance department, through dispersed leadership, therefore, may provide an opportunity to improve safety.

\section{Statement of the Problem}

A successful aviation maintenance department relies on not only the efforts of individual departments but often, the coordination of these entities. However, inefficient communication between groups can create barriers towards the accomplishment of organizational goals (Schmidt, Schmorrow, \& Figlock, 2000), given that individual groups or departments focus solely on those components which fall under their direct responsibility. This environment contributes to unsafe maintenance actions, as supervisors balance the achievement of departmental and organizational goals (Wong, Tjosvold, \& Liu; 2009). While the notion of shared leadership across multiple teams has been examined in a cockpit and cabin crew environment (Benefeld \&Grote, 2014), its application has yet to be applied to an aviation maintenance environment. The specific problem to be examined is whether or not the inclusion of shared leadership in an aviation maintenance MTS environment improves coordination and communication between these entities, resulting in improved safety and efficiency in the accomplishment of organizational goals.

\section{Theoretical Framework}

An appropriate framework to determine whether or not the application of shared leadership in an aviation maintenance MTS environment positively impacts the efficiency of operations, as 
well as safety, would be the Contingency Theory. A traditional, situation-dependent theory of management, the Contingency Theory holds that organizational performance is a function of the interactions between a firm's internal and external constructs (Luthans \& Stewart, 1977). Luthans and Stewart (1977) categorize these constructs as environmental, resource, and management practices. Environmental constructs are factors that affect the organization but are outside of direct control of the organization, such as the location of suppliers or changes in levels of demand. Resource constructs, on the other hand, are factors in which management has more control, such as personnel and equipment. The final construct, management, is defined as any individual in the organization that has the authority to make decisions regarding the allocation of resources, such as the avionics department manager. A mathematical illustration of the Contingency Theory is reported as such; $\mathrm{P}=f(\mathrm{ERM})$ (Longnecker \& Pringle, 1978).

In an aviation maintenance environment, there are many constructs which have the ability to impact performance. The uncertainty of which component will need repair could be considered an environmental construct, given that this element is outside of managerial control. The availability of parts and qualified technicians could be deemed resource constraints, with the actions and policies set forth by maintenance department managers acting as the management construct. With environmental and resource constructs held constant, the application of shared leadership would alter the management construct. Given the parameters of the Contingency Theory, organizational output, or the maintenance repair, should respond with change. Therefore, the Contingency Theory is an appropriate medium for which to examine the impact of shared leadership on an aviation maintenance MTS environment.

\section{Methodology}

A correlational research method, utilizing the Contingency Theory, is recommended in order to determine if shared leadership in an MTS aviation maintenance environment has the potential to positively impact organizational efficiency and safety. Correlational research methods allow the for the examination of multiple variables to determine if one or more have a measurable effect on the outcome. In this case, the inclusion of shared leadership in an existing aviation maintenance MTS environment. Specific, predetermined teams and tasks would be identified, which included several departments within the aviation maintenance environment. For example, a subject matter expert from specific departments which are known to have job tasks which are interrelated such as avionics, powerplants, and airframes. With a shared leadership team intact, circumstances which warrant their expertise would then be identified. Once dispatched, the team would work together to troubleshoot the maintenance error and determine the appropriate steps needed to safety and efficiently address the issue. Each member of the team would work together, collaborate, and determine the safest and most efficient course of action. This work would then be transferred to technicians from each of the required departments for corrective action. Once completed, the leadership team would determine if their recommendation addressed the issue at hand or if additional troubleshooting was needed. By utilizing this leadership team, in an environment which depends on multiple, interrelated departments allows the aircraft malfunction to be examined in the view of several experts, vice one at a time. 


\section{Conclusion/Contribution/Future Recommendations}

This paper contributes to current research in several ways; first, it highlights the importance of effective communication in an aviation maintenance environment. In order to accomplish organizational objectives, many departments must collaborate and work together to efficiently maintain multiple aircraft. Secondly, it identifies gaps within this research area. While other segments of the industry have been examined in this capacity, none have included aviation maintenance departments. While the examination of shared leadership in an MTS aviation maintenance environment is not appropriate for all maintenance actions, those that meet the criteria may provide a suitable environment for which to test the Contingency Theory. Overall, this research supports the notion of shared leadership in an MTS environment; the effective use of proficient and capable leadership in a lateral vice vertical, manner may perhaps minimize safety mishaps in the aviation industry. Research studies are needed, however, to determine if shared leadership in an aviation maintenance MTS environment improves the efficiency and safety of operations through enhanced communication and technical expertise. 


\section{References}

Chandler, T. N. (2000). Navy aviation maintenance intelligent free-play troubleshooting simulations: Capturing the aviation maintenance decision process. Paper presented at the $19^{\text {th }}$ Digital Avionics Systems Conference, Cat. No.00CH37126.

doi:10.1109/DASC.2000.884880

de Vries, T., Hollenbeck, J. R., Davison, R. B., Walter, F., \& van der Vegt, Gerben S. (2016). Managing coordination in multiteam systems: Integrating micro and macro perspectives. Academy of Management Journal, 59(5), 1823-1844. doi:10.5465/amj.2014.0385

Ford, R. C, Heaton, C. P., \& Brown, S. W. 2001. Delivering excellent service: Lessons from the best firms. California Management Review, 44(1):39-56.

Friedrich, T. L., Vessey, W. B., Schuelke, M. J., Ruark, G. A., \& Mumford, M. D. (2009). A framework for understanding collective leadership: The selective utilization of leader and team expertise within networks. The Leadership Quarterly, 20(6), 933-958. doi:10.1016/j.leaqua.2009.09.008

Hambrick, D., \& Mason, P. (1984). Upper Echelons: The Organization as a Reflection of Its Top Managers. The Academy of Management Review, 9(2), 193-206. Retrieved from http://www.jstor.org.ezproxy.libproxy.db.erau.edu/stable/258434

Kouzes, J. M., \& Posner, B. Z. (2007). The leadership challenge (Fourth ed.). San Francisco, CA: Jossey-Bass

Pearce, C. L., \& Barkus, B. (2004). The future of leadership: Combining vertical and shared leadership to transform knowledge work. The Academy of Management Executive, 18(1), 47.

Schmidt, J., Schmorrow, D., \& Figlock, R. (2000). Human factors analysis of naval aviation maintenance related mishaps. Human Factors and Ergonomics Society Annual Meeting Proceedings, 44(22), 775-778.

U.S. Naval Safety Center. (2013). Maintenance causal class a flight mishaps

Wong, A., Tjosvold, D., \& Liu, C. (2009). Cross-functional team organizational citizenship behavior in China: Shared vision and goal interdependence among departments. Journal of Applied Social Psychology, 39(12), 2879. doi:10.1111/j.1559-1816.2009.00554.x 